\title{
Effects of Hypercapnia and Papaverine on Cerebrospinal Fluid Formation and Choroid Plexus Blood Flow
}

\author{
Kenichiro Higashi and Sanao Katayama* \\ Neurosurgical Research Institute, Kitakyushu Central Hospital, Kitakyushu, Fukuoka; \\ ${ }^{*}$ Department of Neurosurgery, Kokura Memorial Hospital, Kitakyushu, Fukuoka
}

\begin{abstract}
Changes in the cerebrospinal fluid (CSF) formation rate (Vf) with hypercapnia and papaverine infusion were measured by the ventriculocisternal perfusion technique in anesthetized dogs. In addition, local blood flow in the choroid plexus and cerebral cortex was measured by the hydrogen clearance method. When $\mathrm{PaCO}_{2}$ increased with $10 \% \mathrm{CO}_{2}$ inhalation, Vf increased transiently and gradually decreased to the control level within an hour. This transient increase in $\mathrm{Vf}$ is considered to be due to mobilizing unequilibrated pools of CSF, caused by sudden changes of the craniospinal blood volume. Excluding such an apparent increase caused by an artifact, neither hypercapnia nor papaverine affected Vf.

Local blood flow of the choroid plexus of 12 normal dogs was $72.8 \pm 13.1 \mathrm{ml} / 100 \mathrm{~g} / \mathrm{min}$ in average which was higher than that of the cerebral cortex; $57.8 \pm 12.4 \mathrm{ml} / 100 \mathrm{~g} / \mathrm{min}$. Although cortical blood flow increased to $225 \%$ of the control under hypercapnia with $10 \% \mathrm{CO}_{2}$ inhalation, the choroid plexus blood flow did not increase significantly. Papaverine infusion also raised the cortical blood flow up to $143 \%$ of the control, while the choroid plexus blood flow did not increase significantly. From the above results, the choroid plexus, a major source of CSF, is demonstrated to be less reactive to vasodilatation induced by either hypercapnia or a vasoactive agent. This phenomenon favorably explanes, at least partially, the unchanged Vf under the effect of hypercapnia or papaverine.
\end{abstract}

Key words: formation of cerebrospinal fluid, hypercapnia, papaverine, choroid plexus blood flow

\section{Introduction}

Cerebrospinal fluid (CSF) is produced at the choroid plexus in its larger portions by a secretory mechanism. Considering the anatomical property of the choroid plexus, which has a rich vasculature, it is assumed that cerebral blood flow (CBF) may be a rate-limiting factor in CSF formation.

It is well known that hypercapnia dilates cerebral vessels to increase CBF. Concerning the effects of hypercapnia upon the rate of CSF formation, however, reported results varied considerably. In the early experiments, Dixon and Halliburton (1913) ${ }^{7}$ reported a marked increase in CSF formation with $\mathrm{CO}_{2}$ inhalation. Oppelt et al. (1963) ${ }^{15)}$ studied the effect of $\mathrm{CO}_{2}$ and reported that marked elevation of $\mathrm{PCO}_{2}$ did not change the rate of $\mathrm{CSF}$ formation measured by the inulin dilution technique. On the other hand, Ames et al. (1965) ${ }^{3)}$ developed a method of volumetric collection of newly formed CSF directly from the surface of the choroid plexus of cats and found that the rate of CSF formation increased to double the control level with $10 \% \mathrm{CO}_{2}$ inhalation. Recently, Hochwald et al. (1973) ${ }^{10)}$ measured the rate of CSF formation using the ventriculocisternal perfusion technique with RISA in cats and reached the same conclusion as Oppelt et al ${ }^{15)}$ had reported; CSF flow did not increase during $10 \% \mathrm{CO}_{2}$ inhalation.

Papaverine hydrochloride is known to be a potent vasodilator to increase $\mathrm{CBF}$. The effect of this drug on the CSF formation, however, has not yet been studied. The present experiments aim to investigate the influence of hypercapnia and papaverine on the rate of CSF formation and local blood flow in the choroid plexus tissue as well as the cerebral cortex. 


\section{Materials and Methods}

Mongrel dogs weighing $8-12 \mathrm{~kg}$ were anesthetized with sodium pentobarbiturate $(30 \mathrm{mg} / \mathrm{kg})$ intravenously, and paralyzed with gallamine triethiodide $(7 \mathrm{mg} / \mathrm{kg})$. Supplemental doses were given as needed. The dogs were artificially ventilated to maintain $\mathrm{PaCO}_{2}$ at $25-30 \mathrm{mmHg}$. Femoral arterial blood pressure was monitored using a pressure transducer (Nihon Kohden, model MPU-0.5). Superior sagittal sinus pressure was monitored through an indwelling catheter from a midline burr hole using a lowpressure transducer (Nihon Kohden, model LPU$0.1)$. For monitoring the internal carotid blood flow rate, the right external carotid artery was ligated at the bifurcation and small branches ramified from the common carotid artery $3 \mathrm{~mm}$ proximal from the bifurcation were all ligated. Then the blood flow rate of the common carotid artery was monitored by an electromagnetic probe, attached at a point $1 \mathrm{~cm}$ proximal from the bifurcation, using an electromagnetic flowmeter (Nihon Kohden, model MF 26).

In order to estimate the rate of CSF formation, ventriculocisternal perfusion was carried out. With the head of each animal immobilized in a stereotactic frame, an opening with a twist drill $2 \mathrm{~mm}$ in diameter was made in the right parietal area, $12 \mathrm{~mm}$ lateral to the sagittal suture and $15 \mathrm{~mm}$ posterior to the coronal suture. The inflow device consisted of a 12gauge blunt-tipped needle with an attached fine polyethylene tube, connected by means of a threeway stopcock to a constant-speed infusion pump and pressure transducer. A micromanipulator successively drove the inflow cannula into a lateral ventricle. An abrupt drop of manometric pressure upon entry into the ventricle assured the proper placement of the cannula. After insertion of the inflow cannula, surgical adhesive sealed the twist-drill hole of the skull. The skin was then incised in the nuchal region and the musculature are separated at the midline. The outflow cannula, an 18-gauge needle attached with a polyethylene tube, was inserted into the cisterna magna through the nuchal ligaments.

With the completed perfusion system, the ventriculocisternal perfusion was continued for 4-6 hours at a fixed rate of approximately $96 \mu \mathrm{l} / \mathrm{min}$. The rate of inflow was measured before and after the perfusion in each experiment. The height of the outlet of the outflow tube was adjusted so as to maintain the hydrostatic pressure within a range of $0-3 \mathrm{mmHg}$. Intraventricular pressure was continuously monitored throughout the experiment. Samples from the outflow cannula was collected at 10-minute intervals. Since the steady-state condition was reached 90 minutes after the beginning of the perfusion, the first nine successive samples were discarded. If blood appeared in the effluent at any time, the experiment was terminated. The quantity of each sample was measured gravimetrically. The perfusion fluid was a balanced salt solution (mock CSF) according to the method of Martins et al. ${ }^{13)}$ To each milliliter of perfusion fluid was added $1 \mathrm{mg}$ of blue dextran. Perfusion fluid was equilibrated with $5 \% \mathrm{CO}_{2}$ in oxygen before use in order to adjust the $\mathrm{pH}$. The concentration of blue dextran in both the perfusate and the effluent was determined by measuring their optical densities with a spectrophotometer (Hitachi, model 102) at a wave length of $610 \mathrm{~nm}$. The rate of CSF formation (Vf) was calculated using the formula derived by Heisey et al. ${ }^{9}$ :

$$
\mathrm{Vf}=\mathrm{Vi} \frac{\mathrm{Ci}-\mathrm{Co}}{\mathrm{Co}}
$$

Where $\mathrm{Ci}$ and $\mathrm{Co}$ are the concentrations of blue dextran in the inflow and outflow fluid, respectively, and $\mathrm{Vi}$ is the rate of perfusion.

After steady state perfusion was established, the two successive samples were collected as a control. Then $\mathrm{PCO}_{2}$ was increased by inhaling $10 \% \mathrm{CO}_{2}$ in air for an hour. In another experiment, papaverine hydrochloride solution $(2 \mathrm{mg} / \mathrm{ml}$ in saline) was infused at a rate of $1 \mathrm{ml} / \mathrm{min}$ for an hour.

Local blood flow rate of the choroid plexus and the cerebral cortex was measured in a separate series of experiments, using the hydrogen clearance technique ${ }^{4)}$ under the condition of $10 \% \mathrm{CO}_{2}$ inhalation or papaverine infusion. The hydrogen electrode consisted of platinum wire, $300 \mu \mathrm{m}$ in diameter, coated with epoxy-resin, the tip of which was attached with a platinum black at a point $1 \mathrm{~mm}$ from the end. Two types of electrodes were used; the one for measuring the cortical blood flow was straight, and the other for measuring the choroid plexus blood flow was bent rectangularly at a point $1 \mathrm{~mm}$ from the end. As a neutral electrode, a disc electrode made of silver chloride was placed in the subcutaneous tissue in the frontal region.

The right cerebral hemisphere of the anesthetized dog was exposed through hemicraniectomy and dural incision. The cortex was excised until the lateral ventricle was unroofed. The hydrogen electrode was lowered to the surface of the exposed choroid plexus using a micromanipulator and its bent tip was surrounded by the plexus tissue. The ventricular cavity was irrigated with warm saline throughout the experiment in order to prevent drying the plexus. Another straight hydrogen electrode was inserted into the left parietal cortex through a twist-drill hole. 
Tissue blood flow was measured by a UH-meter (Unique Medical Co., model D2R-1M) after inhalation of $10 \%$ hydrogen gas for 1 minute. Clearance values, obtained from a clearance curve, were plotted on a hemilogarithmic scale. If the plotted curve showed a monoexponential curve, a half-life was calculated from the curve, and tissue blood flow was calculated from the following formula:

$$
\mathrm{F}=\lambda \frac{0.693}{\mathrm{~T} 1 / 2} \times 100 \quad(\mathrm{ml} / 100 \mathrm{~g} / \mathrm{min}) \cdots \cdots \cdots
$$

Where $\lambda$ is the tissue/blood partition coefficient for the gas. According to Aukland et al., ${ }^{4)}$ it seems likely that $\lambda$ is close to unity in the brain, therefore, the calculation was carried out as $\lambda=1$. If the curve appeared to be biexponential, $\mathrm{T} 1 / 2$ was obtained from both fast and slow components, then $\mathrm{F}$ fast $(\mathrm{Ff})$ and $F$ slow (Fs) were calculated, respectively from formula (2). Total flow was then calculated as follows:

$$
\mathrm{T}=\frac{\mathrm{If}+\mathrm{Is}}{\mathrm{If} / \mathrm{Ff}+\mathrm{Is} / \mathrm{Fs}} \times 100 \quad(\mathrm{ml} / 100 \mathrm{~g} / \mathrm{min}) \cdots(3)
$$

Where, If and Is are points of intersection between fast and slow components and the abscissa, respectively.

\section{Results}

\section{Effects of hypercapnia on CSF formation rate}

The control value of the steady state CSF formation rate before the inhalation averaged $50.2 \pm 3.4$ $\mu \mathrm{l} / \mathrm{min}$ in $8 \mathrm{dogs}$. Changes in the formation rate of CSF following $\mathrm{CO}_{2}$ inhalation are shown in Fig. 1 at 10-minute intervals. The mean values of the rate gradually increased until 20 minutes, showing a peak value of $93.6 \pm 9.4 \mu \mathrm{l} / \mathrm{min}$ for the period of $10-20$ minutes, during $\mathrm{CO}_{2}$ inhalation. Then the rate gradually decreased to the control level by one hour from the beginning of $\mathrm{CO}_{2}$ inhalation. After termination of $\mathrm{CO}_{2}$ inhalation, the $\mathrm{CSF}$ formation rate decreased considerably, but the changes are not statistically significant due to large standard errors.

When $\mathrm{CO}_{2}$ inhalation started, the volume of outflow fluid increased abruptly, reaching more than double that of the control during the first 10-minute interval, and then decreased to the control level after 30 minutes. The outflow fluid suddenly decreased following a switch to room air breathing, then it increased to the control level again after 30 minutes (Fig. 2). The concentration of blue dextran in the effluent decreased transiently and gradually recovered after 30 minutes (Fig. 3).

Changes of some physiological characteristics, such as $\mathrm{PCO}_{2}$ of the arterial blood $\left(\mathrm{PaCO}_{2}\right)$, mean
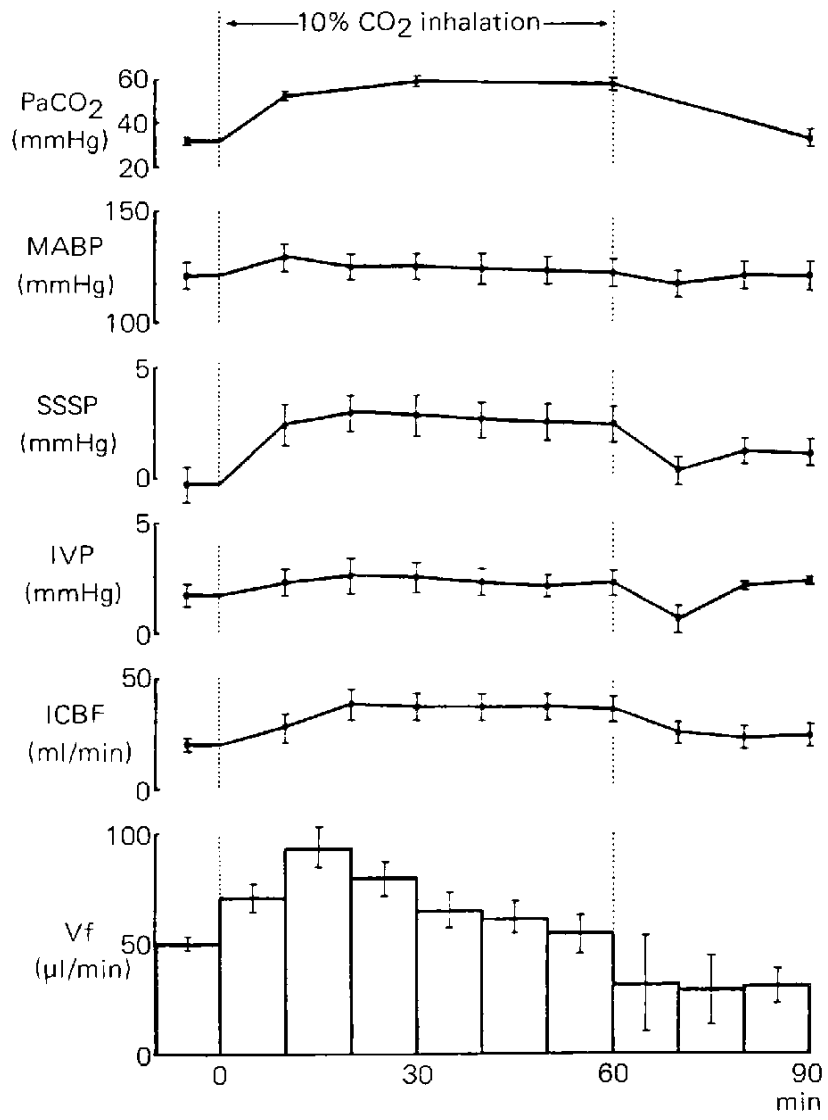

Fig. 1 Changes in physiological parameters and the CSF formation rate ( $\mathrm{Vf}$ ) in 6 anesthetized dogs under hypercapnia induced by $10 \% \mathrm{CO}_{2}$ inhalation. Arterial $\mathrm{PCO}_{2}\left(\mathrm{PaCO}_{2}\right)$, superior sagittal sinus pressure (SSSP) and internal carotid blood flow (ICBF) increased markedly during inhalation of $\mathrm{CO}_{2}$, while mean arterial blood pressure (MABP) and intraventricular pressure (IVP) remained relatively stable. Vf transiently increased and gradually reduced to the control level within 60 minutes during $\mathrm{CO}_{2}$ inhalation.

arterial blood pressure (MABP), superior sagittal sinus pressure (SSSP), intraventricular pressure (IVP), and internal carotid blood flow (ICBF) are also demonstrated in Fig. 1. $\mathrm{PaCO}_{2}$ rapidly increased to reach $58.2 \pm 2.3 \mathrm{mmHg}$ on average, an $85 \%$ increase from the control level of $31.5 \pm 0.9 \mathrm{mmHg}, 30$ minutes after beginning of $\mathrm{CO}_{2}$ inhalation, and maintained the same level for 60 minutes. MABP slightly elevated initially, but this is not statistically significant, while SSSP significantly increased during hypercapnia. After the shift to room air breathing, SSSP fell rapidly, but still maintained a higher level than the control. In comparison with the marked changes of SSSP, IVP showed less changes during $\mathrm{CO}_{2}$ in- 

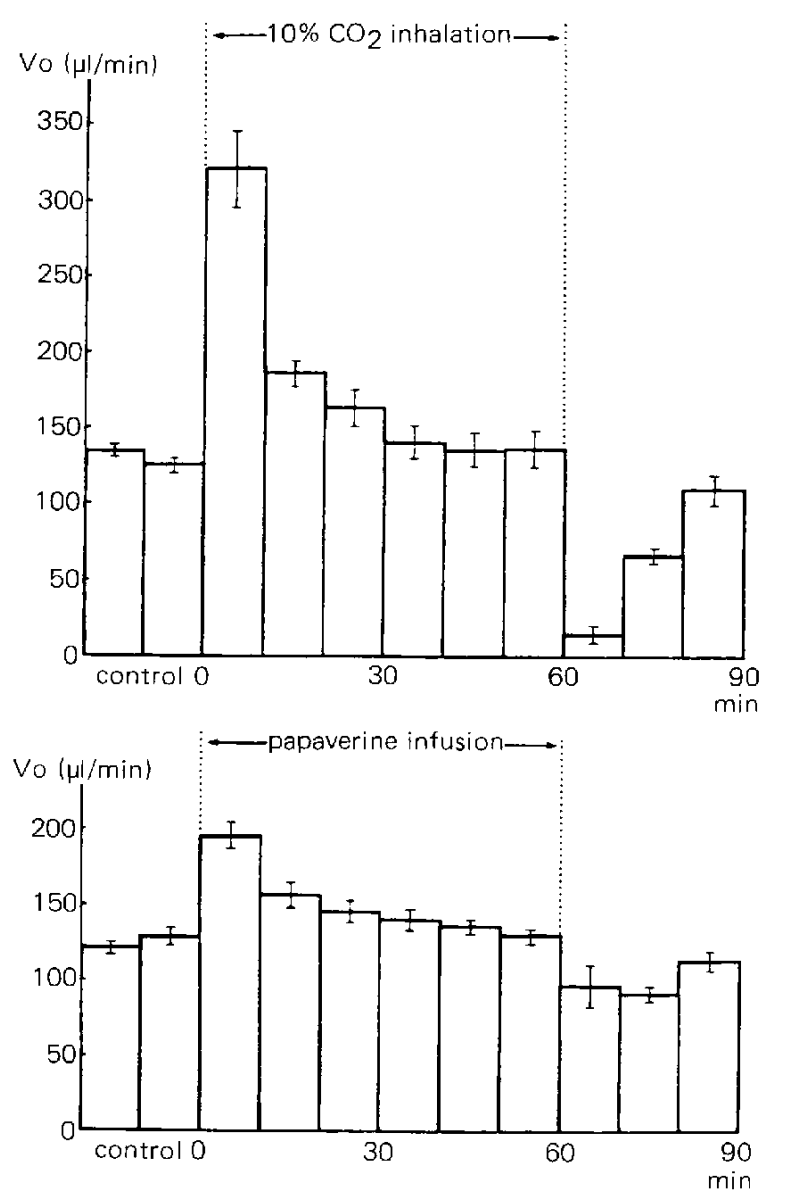

Fig. 2 Volume of outflow fluid from the cisternal cannula (Vo) every 10 minutes before, during and after inhalation of $10 \% \quad \mathrm{CO}_{2}$ (upper) and intravenous infusion of papaverine (lower). There is an immediate and temporary increase in Vo after the beginning of $\mathrm{CO}_{2}$ inhalation and papaverine infusion. When $\mathrm{CO}_{2}$ inhalation or papaverine infusion was ceased, Vo decreased abruptly for 20 minutes. Changes in Vo were more marked in the group of $10 \% \mathrm{CO}_{2}$ inhalation than that of papaverine infusion.

halation. ICBF increased to reach $38.3 \pm 6.5 \mathrm{ml} / \mathrm{min}$ on average, a $91 \%$ increase from the control of $20.1 \pm 3.0 \mathrm{ml} / \mathrm{min}, 20$ minutes after the beginning of $\mathrm{CO}_{2}$ inhalation, and maintained the same level throughout the period of hypercapnia.

\section{Effects of papaverine on CSF formation rate}

The preinfusion control value of the CSF formation rate in the steady state averaged $44.3 \pm 5.3$ $\mu \mathrm{l} / \mathrm{min}$ in 8 dogs. The formation rate slightly increased to reach $55.3 \pm 9.4 \mu \mathrm{l} / \mathrm{min}$ an hour after the beginning of papaverine infusion, $25 \%$ increase from the

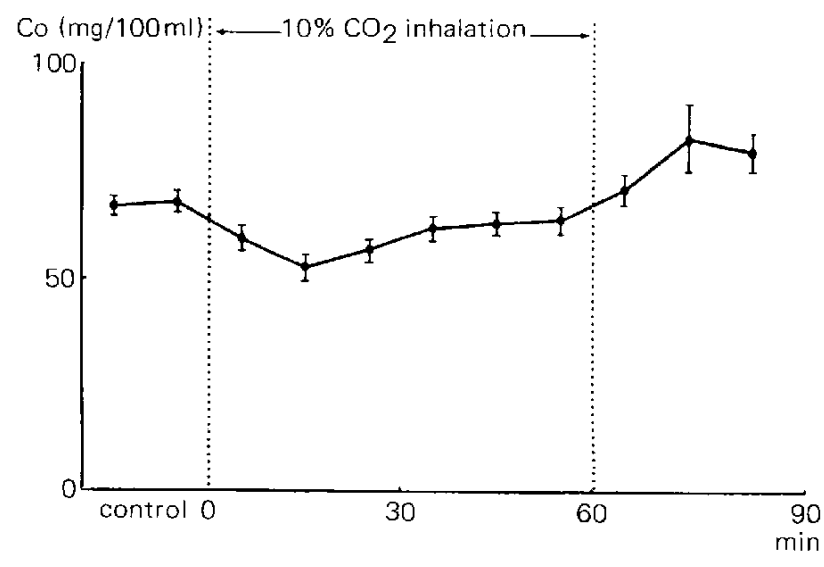

Fig. 3 Concentration of blue dextran in the cisternal outflow fluid (Co) collecting for every 10 minutes before, during and after $10 \% \mathrm{CO}_{2}$ inhalation. In 3 samples taken in initial periods after the beginning of $\mathrm{CO}_{2}$ inhalation, $\mathrm{Co}$ decreased, and it increased after cessation of $\mathrm{CO}_{2}$ inhalation.

control but not statistically significant $(0.1<\mathrm{P}<0.5)$. After termination of infusion, the formation rate suddenly decreased and then returned to the control level after 30 minutes (Fig. 4).

The volume of outflow fluid increased slightly, immediately following papaverine infusion, and decreased to the control level gradually in 60 minutes. Slight decrease of effluent flow occurred transiently when infusion ceased (Fig. 2). MABP progressively decreased to $86 \%$ of the control level $(P<0.05)$. SSSP increased slightly but without any statistical significance. IVP did not change throughout the experiment. ICBF gradually increased to reach $41 \pm 2.9$ $\mathrm{ml} / \mathrm{min}$, a $51 \%$ increase from the control level of $27.1 \mathrm{ml} / \mathrm{min}(\mathrm{P}<0.01), 30$ minutes after the beginning of infusion, and maintained the same level thereafter during the infusion (Fig. 4).

III. Changes in local blood flow in the choroid plexus and the cerebral cortex during $10 \% \mathbf{C O}_{2}$ inhalation and papaverine infusion

Control measurements of local blood flow in the choroid plexus and the cerebral cortex were performed in 12 anesthetized dogs under the condition of MABP $105-140 \mathrm{mmHg}, \mathrm{PaO}_{2} \quad 85-102 \mathrm{mmHg}$ and $\mathrm{PaCO}_{2}$ 32.5-43.5 mmHg. Twelve measurements demonstrated that the choroid plexus blood flow was $72.8 \pm 13.1 \mathrm{ml} / 100 \mathrm{~g} / \mathrm{min}$, and the cortical blood flow was $57.8 \pm 12.4 \mathrm{ml} / 100 \mathrm{~g} / \mathrm{min}$. Thus, the choroid plexus tissue appeared to have $26 \%$ higher blood flow than the cerebral cortex $(0.01<\mathrm{P}<0.05)$.

During $10 \% \mathrm{CO}_{2}$ inhalation in 6 dogs (Group I), 


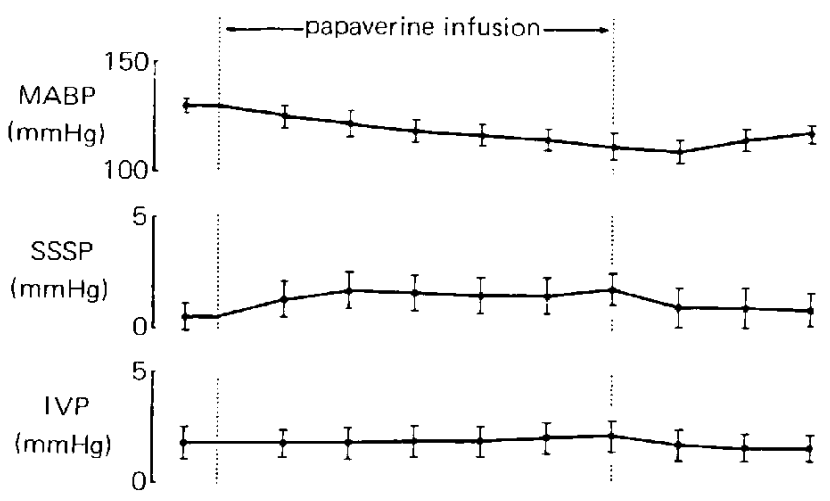

II), cortical blood flow increased to $85.1 \pm 13.3$ and $90.0 \pm 19.1 \mathrm{ml} / 100 \mathrm{~g} / \mathrm{min}$ after 30 and 60 minutes, respectively from the control level of $63.0 \pm 12.5$ $\mathrm{ml} / 100 \mathrm{~g} / \mathrm{min} ; 35$ and $43 \%$ increases from the preinfusion control level $(\mathrm{P}<0.02)$. On the other hand, the choroid plexus blood flow increased only to $81.2 \pm 13.8$ and $82.6 \pm 16.4 \mathrm{ml} / 100 \mathrm{~g} / \mathrm{min}$ after 30 and 60 minutes, respectively from the control level of $76.4 \pm 13.5 \mathrm{ml} / 100 \mathrm{~g} / \mathrm{min}$. These values corresponded to 7 and $8 \%$ increases from the control level, and were not statistically significant. $\mathrm{PaCO}_{2}$ increased to $44.2 \pm 5.5(\mathrm{P}<0.05)$ and $43.2 \pm 1.7 \mathrm{mmHg}(\mathrm{P}<0.01)$ after 30 and 60 minutes, respectively from the control of $37.9 \pm 3.6 \mathrm{~mm} \mathrm{Hg} . \mathrm{PaO}_{2}$ also increased to $98.1 \pm 7.2$ (not significant) and $102.2 \pm 8.3 \mathrm{mmHg} \quad(\mathrm{P}<0.05)$ after 30 and 60 minutes, respectively from the control of $91.9 \pm 6.3 \mathrm{mmHg}$ (Table 2 ).

\section{Discussion}

In our observation, the CSF formation rate increased transiently when $\mathrm{PCO}_{2}$ increased, and it decreased after the lowering of $\mathrm{PCO}_{2}$. Shortly after $\mathrm{CO}_{2}$ inhalation, a transient but marked increase in the volume of outflow fluid occurred. Slightly lagging behind the peak of increase in outflow fluid, the concentration of the blue dextran indicator in the outflow fluid decreased, the time of which coincided with the peak of increase in the CSF formation rate. Induction of hypercapnia increases intracranial blood volume quickly through cerebral vasodilatation ${ }^{23)}$ so that an abrupt increase of intracranial pressure forces out CSF, which is mixed with the perfusion fluid, from the outflowing cannula. Even after the concentration of blue dextran in the outflow fluid becomes stable in the steady state of the perfusion system, CSF in the cortical and spinal subarachnoid space may not be equilibrated with dye. When cerebral and spinal vascular beds increase suddenly, equilibrated CSF with perfusion fluid is forced out of the outflow cannula first, then unequilibrated CSF in the subarachnoid space flows out. Therefore, the first 10minute sample after induction of hypercapnia contains a greater increase of blue dextran than the second one. After the spare CSF in the remote site of the perfusion area flows out, the second steady state is achieved. Such transient increase of volume and subsequent dilution of blue dextran in the outflow fluid may lead to an apparent increase in the CSF formation rate by an artifact. Martins et al ${ }^{(2)}$ observed a similar effect in their experiment on monkeys, and reached the same conclusions. Conversely, the volume of outflow fluid suddenly decreased after the cessation of $\mathrm{CO}_{2}$ inhalation. An abrupt change in the 
Table 1 Blood flow and blood gas values in Group I animals $(n=6)$

\begin{tabular}{|c|c|c|c|c|c|}
\hline \multirow{2}{*}{$\mathrm{CO}_{2}$ inhalation } & \multirow{2}{*}{ MABP (mmHg) } & \multicolumn{2}{|c|}{ Blood flow $(\mathrm{ml} / 100 \mathrm{~g} / \mathrm{min})$} & \multirow{2}{*}{$\mathrm{PaO}_{2}(\mathrm{mmHg})$} & \multirow{2}{*}{$\mathrm{PaCO}_{2}(\mathrm{mmHg})$} \\
\hline & & Cortical & Choroid plexus & & \\
\hline Control & $121 \pm 11$ & $52.6 \pm 10.8$ & $69.2 \pm 12.9$ & $91.1 \pm 5.8$ & $39.9 \pm 3.0$ \\
\hline $30 \mathrm{~min}$ & $130 \pm 12$ & $118.1 \pm 31.0^{*}$ & $79.4 \pm 14.5$ & $101.5 \pm 10.4$ & $63.4 \pm 2.4^{*}$ \\
\hline $60 \mathrm{~min}$ & $130 \pm 12$ & $116.9 \pm 20.7^{*}$ & $78.8 \pm 15.2$ & $107.1 \pm 11.7$ & $67.8 \pm 5.5^{*}$ \\
\hline
\end{tabular}

Values are means \pm standard deviations. Significantly different from control values: ${ }^{*} \mathbf{P}<0.01$.

Table 2 Blood flow and blood gas values in Group II animals $(n=6)$

\begin{tabular}{|c|c|c|c|c|c|}
\hline \multirow{2}{*}{ Papaverine infusion } & \multirow{2}{*}{ MABP (mmHg) } & \multicolumn{2}{|c|}{ Blood flow $(\mathrm{ml} / 100 \mathrm{~g} / \mathrm{min})$} & \multirow{2}{*}{$\mathrm{PaO}_{2}(\mathrm{mmHg})$} & \multirow{2}{*}{$\mathrm{PaCO}_{2}(\mathrm{mmHg})$} \\
\hline & & Cortical & Choroid plexus & & \\
\hline Control & $128 \pm 9$ & $63.0 \pm 12.5$ & $76.4 \pm 13.5$ & $91.9 \pm 6.3$ & $37.9 \pm 3.6$ \\
\hline $30 \mathrm{~min}$ & $135 \pm 7$ & $85.1+13.3^{* *}$ & $81.2 \pm 13.8$ & $98.1 \pm 7.2$ & $44.2 \pm 5.5^{* * *}$ \\
\hline $60 \mathrm{~min}$ & $134 \pm 9$ & $90.0 \pm 19.1^{* *}$ & $82.6 \pm 16.4$ & $102.2 \pm 8.3^{* * *}$ & $43.2 \pm 1.7^{*}$ \\
\hline
\end{tabular}

Values are means \pm standard deviations. Significantly different from control values: ${ }^{*} \mathrm{P}<0.01,{ }^{* *} \mathrm{P}<0.02,{ }^{* * *} \mathrm{P}<0.05$

blood gas content to normocapnia decreases the extent of the intracranial vascular bed, thus a large proportion of inflowing perfusion fluid is used to fill up the expanded fluid space. Such an abnormal condition of fluid dynamics in the perfusion system may lead to erroneous results in the calculated rate of CSF formation. Therefore, disregarding such an artifact, the CSF formation rate is thought to be unchanged during $\mathrm{CO}_{2}$ inhalation.

An increased volume of effluent was also observed in the series of papaverine infusions during the early period of ventriculocisternal perfusion. However, the rate of increase was not enough to ensure an erroneous increase in the CSF formation rate, and papaverine infusion did not alter the CSF formation rate.

The choroid plexus is a highly vascularized tissue projecting into the cerebral ventricles. Its surface is covered by a choroidal epithelium which consists of a single layer of cuboidal cells and forms fine villi. The central core of the villi consists of capillaries. Based on the highly vasculalized structure and its particular localization, the choroid plexus has been considered to be a major site of material exchange between blood plasma and CSF. In fact, the choroid plexus is regarded as a secretory epithelium morphologically and functionally, resembling other fluid-transporting epithelia such as the gall bladder, the small intestine and the renal tubule. ${ }^{6}$ ) The choroid plexus not only secretes CSF but also participates in the regulation of electrolyte transport, ${ }^{2,20)}$ and thus plays an important role in the control of the chemical milieu within the central nervous system.
Concerning the structural basis of CSF formation, Pollay ${ }^{18)}$ proposed a model based on a standing gradient hypothesis. He described that across the wall of large fenestrated capillaries in the choroid plexus, ultrafiltrate of plasma reached to the basement membrane under the influence of the hydrostatic gradient. After the large particles are filtrated by the basement membrane, the filtrate enters the basal infoldings of the choroidal cell, where water flows into the cell by a locally originating osmotic gradient resulting from active transport of sodium. A similar mechanism would then operate to couple solute and solvent movement into the ventricular system via the apical surface of the choroidal cell.

Welch ${ }^{25}$ demonstrated that $25 \%$ of blood plasma entering the choroid plexus is secreted as CSF by the method to measure the hematocrit of venous blood collected from the main draining vein of the choroid plexus. In view of this large extraction, Pappenheimer ${ }^{16)}$ suggested that the volume of secretion of CSF may be limited by the blood supply to the choroid plexus. In this context, if the volume of blood flowing through choroidal capillaries increases by means of vasodilatation, volume of the filtrate of plasma reaching to the basal cell membrane would also increase, and then increase in the rate of CSF formation would be expected.

Contrary to the above expectation, experimental results demonstrated that neither hypercapnia nor papaverine increased the CSF formation rate. In order to explain such a discrepancy, we measured changes in local blood flow in the choroid plexus under vasodilatation due to either $10 \% \mathrm{CO}_{2}$ inhala- 
tion or papaverine infusion. As a result, a few changes were found in the choroid plexus blood flow under these conditions. This was sharply contrasted to the cortical blood flow, which increased markedly in response to either hypercapnia or papaverine infusion.

The advantages of using the hydrogen clearance method to measure local blood flow are that repeated determinations can be quickly made in the same animal under a variety of environmental conditions and pharmacological treatments, and that by use of channel circuit and recorder, local blood flow at several sites can be measured simultaneously ${ }^{17}$. We succeeded in measuring the tissue blood flow of the choroid plexus in the lateral ventricle using the same method as mentioned above. However, problems arise in assessment of the results from this experimentation. First, the influence of intraventricular pressure was ignored in this experiment because the lateral ventricle had been opened before the measurement of the choroid plexus blood flow. Although the effect of hydrostatic pressure cannot be disregarded when hemodynamics of the choroid plexus are studied, the choroid plexus had to be exposed for correct application of the tip of the electrode to this tissue. In fact, blind puncture of the choroid plexus whithin the closed ventricle is extremely difficult. Second, the measured flow rate is the blood flow in localized parts of the choroid plexus, but not that in this tissue as a whole, and if there is a relatively large artery adjacent to the tip of the electrode, it would affect the measured flow rate. The area in which the blood flow is measured by this method is quite limited, at most several millimeters in diameter. Blood flow within such a small portion of the tissue never represents the average blood flow rate of the target tissue. Therefore, if the blood flow of that tissue is not homogeneous, measured data may differ from the average blood flow of that tissue. Although the above mentioned shortcomings exist in this method, its advantage, which may exceed the shortcomings, is that the tissue blood flow can be measured repeatedly in the same individual during changing physiological conditions.

The choroid plexus blood flow was first measured by Welch $^{25}$ in 1963 by a high-speed photography method of the movement of octanol bubble, which had been injected into the exposed main draining vein of the choroid plexus in the lateral ventricle of rabbits. Several investigators later measured the choroid plexus blood flow in cats using radiolabeled microspheres. ${ }^{1,8,22)}$ According to their reports, the choroid plexus blood flow varied between 143 and $301 \mathrm{ml} / 100 \mathrm{~g} / \mathrm{min}$, which was several times higher than the value of the cortical blood flow rate. More recently, Pollay and colleagues ${ }^{19)}$ measured the choroid plexus blood flow by the diffusible indicator technique using ${ }^{123}$ I-iodo-antipyrine and reported that the blood flow rates of the choroid plexus in the lateral ventricle of rabbits and rats were 82 and 85 $\mathrm{ml} / 100 \mathrm{~g} / \mathrm{min}$, respectively. These data are comparable to those from the present experiments; the choroid plexus blood flow in the lateral ventricle of dogs was $72.8 \pm 12.4 \mathrm{ml} / 100 \mathrm{~g} / \mathrm{min}$.

Carbon dioxide is a prominent factor in cerebral circulatory control. When $\mathrm{PaCO}_{2}$ becomes elevated, cerebral blood vessels dilate and $\mathrm{CBF}$ increases. Conversely, lowering $\mathrm{PaCO}_{2}$ leads to constriction of cerebral blood vessels and decrease $\mathrm{CBF} .{ }^{11,21)}$ Symon et al $^{24)}$ reported an increase in CBF by $2-3 \%$ for each $1 \mathrm{mmHg}$ elevation of $\mathrm{PaCO}_{2}$. Contrary to the constant effect of $\mathrm{CO}_{2}$ upon $\mathrm{CBF}$, the effect of hypercapnia on the choroid plexus blood flow remains controversial. Alm and $\mathrm{Bill}^{1)}$ reported that $40 \mathrm{mmHg}$ increase in $\mathrm{PaCO}_{2}$ resulted in a 55\% fall in the choroid plexus blood flow in cats. On the other hand, Pollay et al. ${ }^{19)}$ demonstrated a $30 \mathrm{ml} / 100 \mathrm{~g} / \mathrm{min}$ increase in the choroid plexus blood flow for each 1 $\mathrm{mmHg}$ elevation of $\mathrm{PaCO}_{2}$ in rabbits.

In the present experiments, an increase in the choroid plexus blood flow in response to hypercapnia was slight; a $28 \mathrm{mmHg}$ rise in $\mathrm{PaCO}_{2}$ resulted in only a $15 \%$ increase in the choroid plexus blood flow. This contrasted sharply to the more than doubled cortical blood flow which was simultaneously measured during $10 \% \mathrm{CO}_{2}$ inhalation. From this result, we concluded that blood vessels in the choroid plexus have less $\mathrm{CO}_{2}$ reactivity than cortical vessels, at least at the capillary level.

Papaverine is known as a potent vasodilator. Numerous animal experiments have shown that it can produce cerebral vasodilatation by acting directly on arterial smooth muscles. In the human brain, using the radioactive xenon clearance method, McHenry et $a l .^{14)}$ and Capon et $a l .^{5)}$ reported 18 and $23.3 \%$ increases of regional blood flow, respectively after intravenous administration of papaverine. In the present experiments, the cortical blood flow increased $43 \%$ by infusion of papaverine. Since papaverine elevated $\mathrm{PaCO}_{2}$ from 38 to $43 \mathrm{mmHg}$, the effect of $\mathrm{CO}_{2}$ cannot be dismissed. However, the increase in the cortical blood flow was larger than that expected by such a slight elevation of $\mathrm{PaCO}_{2}$. On the other hand, the choroid plexus blood flow increased only $8 \%$ after the administration of papaverine, which is in quite a contrast to the marked increase in cortical blood flow after papaverine infusion. Therefore, it is thought that the blood vessels of the choroid plexus have also 
less reactivity to vasodilator drugs, similar to the $\mathrm{CO}_{2}$ reactivity.

In conclusion, sudden changes of the craniospinal blood volume can lead to apparent changes in the CSF formation rate caused by an artifact. By neglecting such an apparent increase at the initial stage, neither hypercapnia nor papaverine produced any changes in the CSF formation rate. On the other hand, the local blood flow in the choroid plexus, measured by the hydrogen clearance method, was less affected by either $10 \% \mathrm{CO}_{2}$ inhalation or by intravenous infusion of papaverine. This occurred in contrast to a marked increase in the cortical blood flow under the same conditions. Such a difference in the reactivity against vasodilatation between the cortical and the choroid plexus vessels may account partly for the less significant increase in the reaction of the CSF formation rate to hypercapnia or papaverine.

\section{References}

1) Alm A, Bill A: The effect of stimulation of the cervical sympathetic chain on retinal oxygen tension and on uveal, retinal and cerebral blood flow in cats. Acta Physiol Scand 88: 84-94, 1973

2) Ames A III, Higashi K, Nesbett FB: Relation of potassium concentration in choroid plexus fluid to that in plasma. $J$ Physiol (London) 181: 506-515, 1965

3) Ames A III, Higashi K, Nesbett FB: Effects of $\mathrm{PCO}_{2}$, acetazolamide and ouabain on volume and composition of choroid plexus fluid. J Physiol (London) 181: 516-524, 1965

4) Aukland K, Bower BF, Berliner RW: Measurement of local blood flow with hydrogen gas. Circ Res 14: 164187, 1964

5) Capon A, De Rood M, Vervist A, Fruhling J: Action of vasodilator on regional cerebral blood flow in subacute or chronic cerebral ischemia. Stroke 8: 2529, 1977

6) Cserr HF: Physiology of the choroid plexus. Physiol Rev 51: 273-311, 1971

7) Dixon WE, Halliburton WD: The cerebrospinal fluid. I. Secretion of the fluid. J Physiol (London) 47: 215242,1913

8) Haywood JR, Vogh BP: Some measurement of autonomic nervous system influence on production of cerebrospinal fluid in the cat. $J$ Pharmacol Exp Ther 208: 341-346, 1979

9) Heisey SB, Held D, Pappenheimer JR: Bulk flow and diffusion in the cerebrospinal fluid system of the goat. Amer J Physiol 203: 775-781, 1962

10) Hochwald GM, Malhan C, Brown J: Effect of hypercapnia on CSF turnover and blood-CSF barrier to ptotein. Arch Neurol (Chicago) 28: 150-155, 1973

11) Lassen NA: Cerebral blood flow and oxygen consumption. Physiol Rev 39: 183-239, 1959
12) Martins AN, Newby N, Doyle TF: Source of error in measuring cerebrospinal fluid formation by ventriculocisternal perfusion. $J$ Neurol Neurosurg Psychiat 40: 645-650, 1977

13) Martins AN, Ramirez A, Doyle TF: Comparison of radio-iodinated serum albumin and blue dextran as indicators to measure rate of formation of cerebrospinal fluid. Exp Neurol 47: 249-256, 1975

14) McHenry LC Jr, Jaffe ME, Kawamura J, Goldberg HI: Effect of papaverine on regional blood flow in focal vascular disease of the brain. New Eng $J$ Med 282: 1167-1170, 1970

15) Oppelt WW, Maren TH, Owens ES, Rall DP: Effects of acid-base alterations on cerebrospinal fluid production. Proc Soc Exp Biol Med 114: 86-87, 1963

16) Pappenheimer JR: Personal communication, cited in 3)

17) Pasztor E, Symon L, Dorsch NWC, Branston NM: The hydrogen clearance method in assessment of blood flow in cortex, white matter and deep nuclei of baboons. Stroke 4: 556-567, 1973

18) Pollay M: Formation of cerebrospinal fluid. Relation of studies of isolated choroid plexus to the standing gradient hypothesis. J Neurosurg 42: 665-673, 1975

19) Pollay M, Stevens FA, Roberts PA: Alteration in choroid plexus blood flow and cerebrospinal fluid formation by increased ventricular pressure, in Wood JH (ed): Neurobiology of Cerebrospinal Fluid II. New York, Plenum, 1983, pp 687-695

20) Reed DJ, Yen M-H: The role of the cat choroid plexus in regulating cerebrospinal fluid magnesium. $J$ Physiol (London) 281: 477-485, 1978

21) Reivich $\mathrm{M}$ : Arterial $\mathrm{PCO}_{2}$ and cerebral hemodynamics. Amer J Physiol 206: 25-35, 1959

22) Shulman $K$, Furman $M$, Rosende $R$ : Regional cerebral blood flow. Evaluation of the microsphere technique, in Langfitt T, McHenry LC Jr, Reivich M, Wallman $\mathrm{H}$ (eds): Cerebral Circulation and Metabolism. New York, Splinger, 1975, pp 148-151

23) Smith AL, Neufeld GR, Ominsky AJ, Wollman H: Effect of arterial $\mathrm{CO}_{2}$ tension on cerebrospinal blood flow, mean transit time, and vascular volume. $J A p p l$ Physiol 31: 701-707, 1971

24) Symon L, Pasztor E, Dorsch NWC, Branston NM: Physiological responses of local areas of the cerebral circulation in experimental primates determined by the method of hydrogen clearance. Stroke 4: 632-642, 1973

25) Welch K: Secretion of cerebrospinal fluid by choroid plexus of the rabbit. Amer $J$ Physiol 205: 617-624, 1963

Address reprint requests to: K. Higashi, M.D., Department of Neurosurgery, Kitakyushu Central Hospital, 1-4-5 Shiragane, Kokurakita-ku, Kitakyushu, Fukuoka 802 , Japan. 